УДК 621.43.013

\title{
ЗНИЖЕННЯ ВИТРАТИ ПАЛИВА ТА СКОРОЧЕННЯ ВИКИДІВ ШКІДЛИВИХ РЕЧОВИН 3 ВІДПРАЦЬОВАНИМИ ГАЗАМИ ЗА РАХУНОК ВИЗНАЧЕННЯ РАЦІОНАЛЬНИХ КУТІВ ВИПЕРЕДЖЕННЯ ЗАПАЛЮВАННЯ
}

К-т техн. наук В.А. Корогодський, аспір. О.М. Стеценко, наук. співроб. НТУ «ХПІ» С.В. Обозний.

\section{СНИЖЕНИЕ РАСХОДА ТОПЛИВА И СОКРАЩЕНИЕ ВЫБРОСОВ ВРЕДНЫХ ВЕЩЕСТВ С ОТРАБОТАВШИМИ ГАЗАМИ ЗА СЧЕТ ОПРЕДЕЛЕНИЯ РАЦИОНАЛЬНЫХ УГЛОВ ОПЕРЕЖЕНИЯ ЗАЖИГАНИЯ}

К-т техн. наук В.А. Корогодский, аспир. О.Н. Стеценко, науч. сотр. НТУ «ХПИ»С.ВОбозный

\section{REDUCING THE FUEL CONSUMPTION AND REDUCTION EMISSION EXHAUST GASES BY DEFINITION OF RATIONAL SPARK TIMING}

Cand. of techn. sciences V.A. Korohodskiy, postgraduate O.N. Stetsenko, research associate NTU "KPI"S.V. Obozniy •

На основі експериментальних досліджень по навантажувальній характеристиці двотактного двигуна з іскровим запалюванням при безпосередньому вприскуванні палива $i$ організації згоряння розмарованого паливно-повітряного заряду визначені раціональні кути випередження запалювання по мірі зміни навантаження, щуо дозволяе знизити витрату палива та скоротити викиди шкідливих речовин з відпрацьованими газами.

Ключові слова: навантажувальна характеристика, кут випередження запалювання, зниження витрати палива, двотактний двигун.

На основании экспериментальных исследований по нагрузочной характеристике двухтактного двигателя с искровым зажиганием при непосредственном впрыскивании топлива и организации сгорания расслоенного топливно-воздушного заряда определень рациональные угль опережения зажигания по мере изменения нагрузки, что позволяет снизить расход топлива и сократить выбросы вредных веществ с отработавшими газами.

Ключевые слова: нагрузочная характеристика, угол опережения зажигания, снижение расхода топлива, двухтактный двигатель.

Using the engine power system with direct fuel injection for the spark-ignition engines, helps to reduce the fuel consumption and emission of the exhaust gases. It especially suitable to use for the two-stroke engines with direct injection, wherein it determines the reduction of loss of fuel into the exhaust system for the scavenging cylinder. Thus, the organization of stratified fuel-air charge allows to efficiently burn the fuel-air mixture, which further reduces the fuel consumption and performance of modern requirements for emissions. The start of ignition of fuel-air mixture corresponds to the ignition-timing angle, which affects the intensity of the processes of combustion and fuel and environmental performance of the engine.

Based on experimental researches of the two-stroke spark-ignition engine loading characteristic, with the direct fuel injection and combustion organization stratified fuel-air charge to the load characteristic modes with $n=3000 \mathrm{~min}^{-1}$, the rational moment of the fuel supply 
defined. At a given angle were set to rational angles ignition as the load varies, thus reducing fuel consumption and reduce emissions in exhaust gases.

Keywords: fuel consumption, spark timing, spark-ignition engines, exhaust, direct-injection, stratified charge.

\section{Введение и актуальность} проблемы. Использование в двигателях с искровым зажиганием (ИЗ) системы питания с непосредственным впрыскиванием топлива (НВТ) позволяет снизить расход топлива и сократить содержание вредных веществ (BВ) в отработавших газах (ОГ). Особенно целесообразно применение НВТ в двухтактных двигателях, что предопределяет исключение потерь топлива в выпускную систему при продувке цилиндра. При этом организация расслоенного топливновоздушного заряда (РТВ3) позволяет эффективно сжигать топливно-воздушную смесь (ТВC), что дополнительно обеспечивает снижение расхода топлива и выполнение современных требований по токсичности ОГ. Момент начала воспламенения ТВС соответствует значению

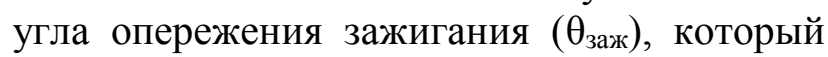
влияет на интенсивность протекания процессов сгорания и на топливноэкологические показатели двигателя, поэтому проведение исследований по

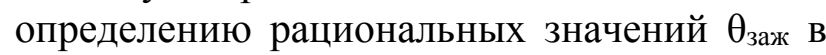
зависимости от режима работы двигателя является актуальной проблемой.

Анализ публикаций и определение направления исследований. Исследования по индикаторным диаграммам показателей двигателей с ИЗ и внешним смесеобразованием свидетельствуют о том, что при обеднении ТВС $(\alpha>1,2)$ протекание процессов сгорания в последовательных циклах становится менее идентичным, снижается эффективность протекания процессов горения, что обуславливает неустойчивость работы двигателя и увеличение расхода топлива [1]. Для повышения эффективности протекания процессов сгорания увеличивают угол

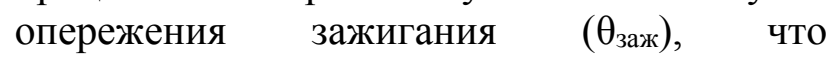
способствует уменьшению не идентичности последовательных циклов и снижению расхода топлива.

Проведенные исследования по влиянию момента начала воспламенения $\left(\theta_{\text {заж}}\right)$ при обедненном и обогащенном составе ТВC на показатели сгорания

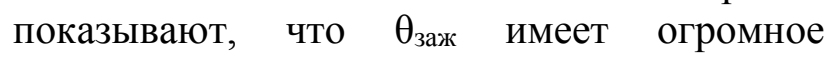
влияние на дальнейшее протекание процессов сгорания. Момент начала воспламенения влияет на величину максимального давления в цилиндре двигателя относительно ВМТ и соответственно на значения среднего индикаторного давления, которое характеризует уровень форсирования рабочего цикла двигателя и его топливную экономичность $[2,10]$.

Своевременное тепловыделение при сгорании обеспечивает максимальную работу цикла. Величина значения $\theta_{\text {заж }}$ характеризует продолжительность начальной фазы сгорания. При интенсивном протекании процессов сгорания в начальной

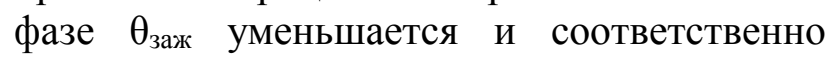
наоборот увеличивается при снижении скорости сгорания и возрастания давления в цилиндре по углу поворота коленчатого вала $(\mathrm{dp} / \mathrm{d} \varphi)[3,11]$.

Современные

результаты исследований двигателей с ИЗ и НВТ показывают, что организация РТВ3 позволяет получить меньший расход топлива и более низкое содержание ВВ в ОГ, чем при организации обедненного гомогенного состава ТВС по всему объему цилиндра $[4,5$, $8,9]$.

Различные способы организации процессов внутреннего смесеобразования с РТВ3 при НВТ в цилиндр двигателя с ИЗ имеют свои индивидуальные особенности. Формирование ТВС, обусловленное направленным движением потоков рабочего тела в цилиндре двигателя по отношению к месту расположения электродов свечи зажигания. При этом состав ТВС, количество остатков продуктов сгорания, параметры рабочего тела и интенсивность турбулизации в зоне горения определяют эффективность протекания процессов сгорания РТВ3.

С целью организации эффективного сгорания топлива разработан новый способ 
смесеобразования и сгорания РТВ3, который позволяет осуществить распределение ТВС в объеме цилиндра таким образом, что например, при значениях коэффициента избытка воздуха в цилиндре $\alpha_{\text {цил }}>1,5$ состав ТВC возле электродов свечи зажигания находится в диапазоне надежного воспламенения с $\alpha=0,8 \div 1,0$. При протекании основной фазы сгорания в зону пламени интенсивно подводится воздух [6].

При изменении цикловой подачи топлива соответственно изменяется режим работы двигателя и состав ТВС. Поэтому, для получения потенциально более высоких топливно-экологических показателей двигателя в определенном диапазоне нагрузок необходимо проведение экспериментальных исследований по определению рационального момента начала воспламенения $\left(\theta_{\text {заж) }}\right)$ TBC.

Целью работы является получение наилучших топливно-экологических показателей двухтактного двигателя с ИЗ при НВТ и организации РТВЗ на основных эксплуатационных режимах работы.

Задачами настоящих исследований является экспериментальное определение рациональных углов опережения зажигания

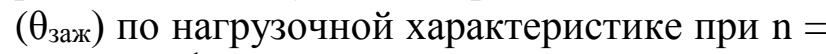
3000 мин $^{-1}$.

Анализ результатов исследований. Результаты исследований экспериментальных одноцилиндрового двухтактного двигателя ДН-4M (S/D=87/82) c ИЗ, кривошипно-камерной продувкой, воздушного охлаждения при использовании системы питания с HBT получены на кафедре ДВС НТУ «ХПИ».

Поскольку зона

эксплуатационных режимов работы двигателя находится в диапазоне частот вращения коленчатого вала при $\mathrm{n}=2000 \div 3000$ мин $^{-1}$ и, двигатель может быть использован в качестве привода генератора для миниэлектростанции, а выработанная ею электроэнергия предполагается в частности использоваться в электросварочных агрегатах, где нагрузка изменяется в широком диапазоне от минимальных до максимальных значений, то исследования проводились по нагрузочной характеристике при $\mathrm{n}=3000 \mathrm{Mин}^{-1}$. Для снижения себестоимости выработанной электроэнергии использовался более дешевый низкооктановый бензин А-80.

По предварительным экспериментальным исследованиям с точки зрения наименьшего расхода топлива и минимального количества выбросов ВВ в ОГ определено, что на режимах нагрузочной характеристики при $\mathrm{n}=3000$ мин $^{-1}$ целесообразно устанавливать момент начала подачи топлива $\varphi_{\text {впр }}=224$ гр. пкв после ВМТ [7]. При данном угле начала впрыскивания топлива исследования проводились с фиксированной установкой угла опережения зажигания $\theta_{\text {заж }}=8,10$ и 15 гр. пкв до ВМТ (рис. 1-3).

На режимах минимальных нагрузок до $\mathrm{P}_{\mathrm{e}}=0,145$ МПа для определения наивыгоднейшего угла опережения зажигания с целью получения минимального расхода топлива в этом диапазоне нагрузок достроены кривые $\mathrm{g}_{\mathrm{e}}$ по линиям тренда при $\theta_{\text {заж }}=8$ гр. пкв до ВМТ и $\theta_{\text {заж }}=10$ гр. пкв до ВMT (рис. 1). Более предпочтительный характер изменения кривой с минимальными значениями расхода топлива представляется при установке $\theta_{\text {заж}}=8$ гр. пкв до ВМТ.

$\mathrm{B}$ диапазоне частичных нагрузок от $\mathrm{P}_{\mathrm{e}}$ $=0,145$ МПа до $\mathrm{P}_{\mathrm{e}}=0,2$ МПа с изменением

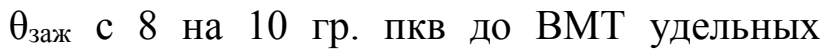
эффективный расход топлива снижается до $\mathrm{g}_{\mathrm{e}}=256 \Gamma /(\kappa В \mathrm{~T} \cdot \mathrm{\varphi})$. А при установке $\theta_{\text {заж }}=15$ гр. пкв до ВМТ расход топлива с уменьшением нагрузки в этом диапазоне нагрузок возрастает более, чем на $12 \%$. Характер изменения $\mathrm{g}_{\mathrm{e}}$ в зависимости от установленных углов опережения зажигания $\left(\theta_{\text {заж}}=8,10\right.$ и 15 гр. пкв до ВМТ) согласуется c изменением значений коэффициента избытка воздуха в цилиндре $\left(\alpha_{\text {цил }}\right)$ двигателя. Так, при установке $\theta_{\text {заж }}=8$ гр. пкв до ВМТ значения $\alpha_{\text {цил }} \mathrm{c}$ повышением нагрузки до $\mathrm{P}_{\mathrm{e}}=$ 0,2 МПа увеличиваются до 1,8 , при $\theta_{\text {заж }}=10$ гр. пкв до ВМТ до $\alpha_{\text {цил }}=1,96$, а при $\theta_{\text {заж }}=15$ гр. пкв до ВМТ возрастают до $\alpha_{\text {цил }}=1,62$ (рис. 1). Также более эффективное протекание процессов сгорания в этом диапазоне нагрузок наблюдается при $\theta_{\text {заж }} 10$ гр. пкв до ВМТ, что подтверждается более низкой температурой ОГ $\left(\mathrm{t}_{\text {ог }}=266{ }^{\circ} \mathrm{C}\right.$ при $\mathrm{P}_{\mathrm{e}}$ $=0,2$ МПа) по отношению к установленным $\theta_{\text {заж }}=8$ гр. пкв до ВМТ $\left(\mathrm{t}_{\text {ог }}=269{ }^{\circ} \mathrm{C}\right.$ при 
$\mathrm{P}_{\mathrm{e}}=0,2$ МПа) и $\theta_{\text {заж}}=15$ гр. пкв до ВМТ $\left(\mathrm{t}_{\text {ог }}=\right.$ $276{ }^{\circ} \mathrm{C}$ при $\mathrm{P}_{\mathrm{e}}=0,2 \mathrm{MПа).} \mathrm{При} \mathrm{этом} \mathrm{с} \theta_{\text {заж }} 10$ гр. пкв до ВМТ ниже температура поверхности камеры сгорания $\left(\mathrm{t}_{\mathrm{\kappa c}}=155^{\circ} \mathrm{C}\right)$ по отношению к $\theta_{\text {заж }}=8$ гр. пкв до BMT $\left(\mathrm{t}_{\mathrm{\kappa c}}=\right.$ $\left.159^{\circ} \mathrm{C}\right)$ и $\theta_{\text {заж }}=15$ гр. пкв до BMT $\left(\mathrm{t}_{\mathrm{\kappa c}}=168\right.$ $\left.{ }^{\circ} \mathrm{C}\right)$ (рис. 2). Также и меньше содержание $\mathrm{CO}$ и $\mathrm{CH}$ в ОГ при $\theta_{\text {заж }} 10$ гр. пкв до $\mathrm{BMT}(0,02$ $\%$ и до 15 ppm соответственно) по отношению к $\theta_{\text {заж }}=8$ гр. пкв до ВМТ $(\mathrm{CO}=$ $0,03 \%, \mathrm{CH}=30 \mathrm{ppm})$ и $\theta_{\text {заж }}=15$ гр. пкв до BMT $(\mathrm{CO}=0,04 \%, \mathrm{CH}=40$ ppm $)$ (рис. 3).

Таким образом, в диапазоне частичных нагрузок от $\mathrm{P}_{\mathrm{e}}=0,145 \mathrm{MПа} \mathrm{до}$ $\mathrm{P}_{\mathrm{e}}=0,2$ МПа $\mathrm{c}$ точки зрения более эффективного протекания процессов сгорания РТВ3, что характеризуется наименьшим расходом топлива и минимальным содержанием $\mathrm{BB}$ в ОГ целесообразно устанавливать момент начала подачи топлива $\varphi_{\text {впр }}=224$ гр. пкв после ВМТ и значение угла опережения зажигания $\theta_{\text {заж}}=$ 10 гр. пкв до ВМТ.

$\mathrm{B}$ диапазоне частичных нагрузок от $\mathrm{P}_{\mathrm{e}}$ $=0,2 \mathrm{MПа} \mathrm{до} \mathrm{P}_{\mathrm{e}}=0,28 \mathrm{MПа} \mathrm{минимальные}$ значения расхода топлива также получены при $\theta_{\text {заж }} 10$ гр. пкв до ВМТ, однако, с повышением нагрузки проявлются тенденции повышения как $\mathrm{g}_{\mathrm{e}}$, так и содержания $\mathrm{CH}$ в ОГ при постоянных значениях CO.

При этом с установкой $\theta_{\text {заж }}=15$ гр. пкв до ВМТ с повышением нагрузки до $\mathrm{P}_{\mathrm{e}}=$ 0,284 МПа расход топлива резко снижается до $\mathrm{g}_{\mathrm{e}}=259 \mathrm{\Gamma} /(\mathrm{\kappa В \textrm { \tau }} \mathrm{q})$ и становится меньшим по сравнении с установкой $\theta_{\text {заж }}=10$ гр. пкв до ВМТ. Дальнейшее повышение нагрузки при $\theta_{\text {заж }}=15$ гр. пкв до ВМТ до $\mathrm{P}_{\mathrm{e}}=0,34$ МПа приводит к снижению $\mathrm{g}_{\mathrm{e}}$ 252 г/(кВт·ч), содержанию $\mathrm{CO}$ до $0,4 \%$ и $\mathrm{CH}$ до $40 \mathrm{ppm}$ в ОГ, что меньше, чем при $\theta_{\text {заж }}=$ 10 гр. пкв до ВМТ $\left(\mathrm{g}_{\mathrm{e}}=262\right.$ г/(кВт·ч), $\mathrm{CO}=$ $0,5 \%$ и $\mathrm{CH}=45 \mathrm{ppm})$. Снижение расхода топлива и содержание ВВ в ОГ обусловлено более высокими значениями $\alpha_{\text {цил }}=1,71\left(\theta_{\text {заж }}\right.$ $=15$ гр. пкв до ВМТ) по сравнению $\mathrm{c}$ $\alpha_{\text {цил }}=1,62\left(\theta_{\text {заж }}=10\right.$ гр. пкв до ВМТ).

Более высокие значения $\alpha_{\text {цил }}$ предопределили наиболее эффективное протекание процессов сгорания РТВЗ. Полученные данные согласуются с тепловыми потерями при различных углах опережения зажигания. Так, практически при одинаковых значениях температур поверхностей камеры сгорания $\left(\mathrm{t}_{\mathrm{\kappa c}} \sim 195^{\circ} \mathrm{C}\right)$ при различных углах опережения зажигания $\left(\theta_{\text {заж }}=8,10\right.$ и 15 гр. ПКв до ВМТ), что характеризуется соизмеримым уровнем тепловых потерь в стенки надпоршневого объема, температура ОГ при $\theta_{\text {заж }}=15$ гр. пкв до BMT $\left(\mathrm{t}_{\text {ог }}=311^{\circ} \mathrm{C}\right)$ ниже, чем при $\theta_{\text {заж }}=10$ гр. пкв до ВМТ $\left(\mathrm{t}_{\text {ог }}=327^{\circ} \mathrm{C}\right)$ и при $\theta_{\text {заж }}=10$ гр. пкв до ВМТ $\left(\mathrm{t}_{\text {ог }}=345^{\circ} \mathrm{C}\right)$.

В диапазоне повышенных нагрузок значения удельного эффективного расхода топлива и количество содержания ВВ в ОГ при $\theta_{\text {заж }}=15$ гр. пкв до ВМТ ниже, чем при $\theta_{\text {заж }}=8$ и 10 гр. пкв до ВМТ, что объясняется благоприятным увеличением времени на протекание процессов смесеобразования и сгорания РТВ3 при увеличении цикловой подачи топлива. При этом, установка $\theta_{\text {заж }}=15$ гр. пкв до ВМТ позволила повысить максимальную нагрузку на двигатель до $\mathrm{P}_{\mathrm{e}}=0,476 \mathrm{MПа,} \mathrm{что} \mathrm{на} 10 \%$ выше, чем при $\theta_{\text {заж }}=10$ гр. пкв до ВМТ и на $12 \%$ выше, чем при $\theta_{\text {заж }}=8$ гр. пкв до ВМТ.

Необходимо отметить, что для получения наиболее лучших показателей по расходу топлива и выбросам ВВ в ОГ в диапазоне частичных нагрузок от $\mathrm{P}_{\mathrm{e}}=0,2$ МПа до $\mathrm{P}_{\mathrm{e}}=0,34$ МПа целесообразно устанавливать угол опережения зажигания между 10 и 15 гр. пкв до ВМТ. Предполагается, что установка угла опережения зажигания в интервале от 12 до 13 гр. пкв до ВМТ позволит получить расход топлива в этом диапазоне работы двигателя на уровне $\mathrm{g}_{\mathrm{e}}=250 \quad$ г/(кВТ.ч), о чем свидетельствует построенная усредненная по минимальным значениям расхода топлива $\left(\mathrm{g}_{\mathrm{e}}\right)$ кривая. Также для получения наименьшего расхода топлива и выбросов BB в ОГ при изменении нагрузки построена усредненная кривая коэффициента избытка воздуха в цилиндре двигателя, максимальное значение в результате составляет $\alpha_{\text {цил }}=1,98$ при $\mathrm{P}_{\mathrm{e}}=0,22 \div 0,23 \mathrm{MПа} \mathrm{(рис.} 1$ ).

Общие выводы. На режимах нагрузочной характеристики при $\mathrm{n}=3000$ мин $^{-1}$ для получения наименьшего расхода топлива и минимальных выбросов ВB в ОГ на двухтактном двигателе ДН-4М с искровым зажиганием при организации 
внутреннего смесеобразования и сгорания расслоенного топливно-воздушного заряда целесообразно устанавливать момент начала подачи топлива $\varphi_{\text {впр }}=224$ гр. пкв после ВМТ при следующих углах опережения зажигания: на режимах минимальных нагрузок до $\mathrm{P}_{\mathrm{e}}=0,145 \mathrm{MПа}-\theta_{\text {заж }}=8$ гр. пкв до ВМТ; в диапазоне частичных нагрузок при $\mathrm{P}_{\mathrm{e}}=0,145 \div 0,2 \mathrm{MПа}-\theta_{\text {заж }}=10$ гр. пкв до ВМТ; при $\mathrm{P}_{\mathrm{e}}=0,2 \div 0,34 \mathrm{MПа}-\theta_{\text {заж }}=13$ гр. пкв до ВМТ; при $\mathrm{P}_{\mathrm{e}}=0,34 \div 0,476$ Мпа$\theta_{\text {заж }}=15$ гр. пкв до ВМТ.

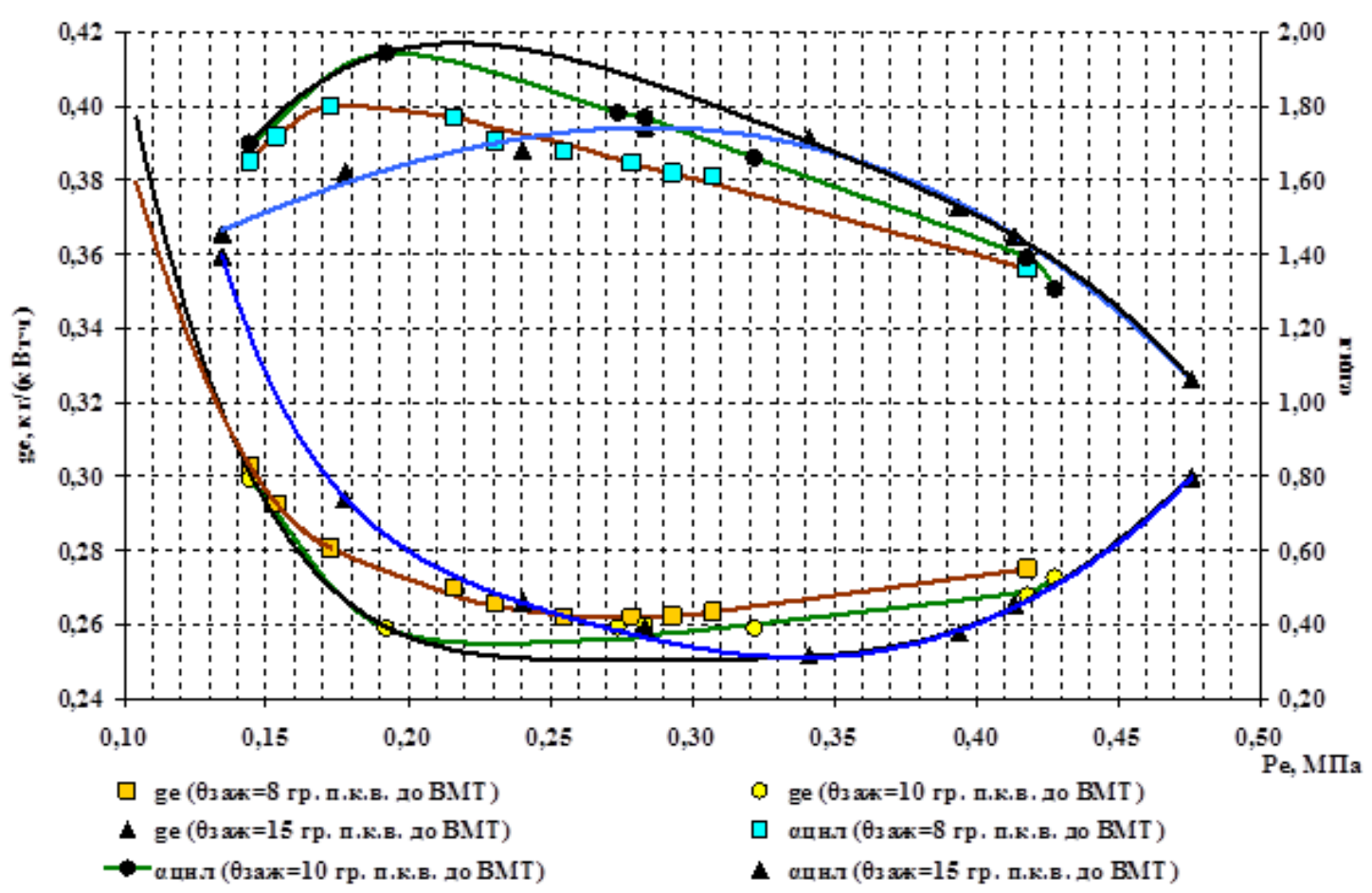

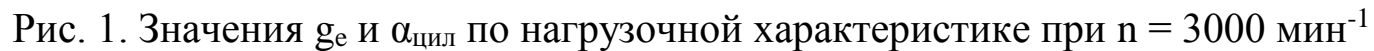

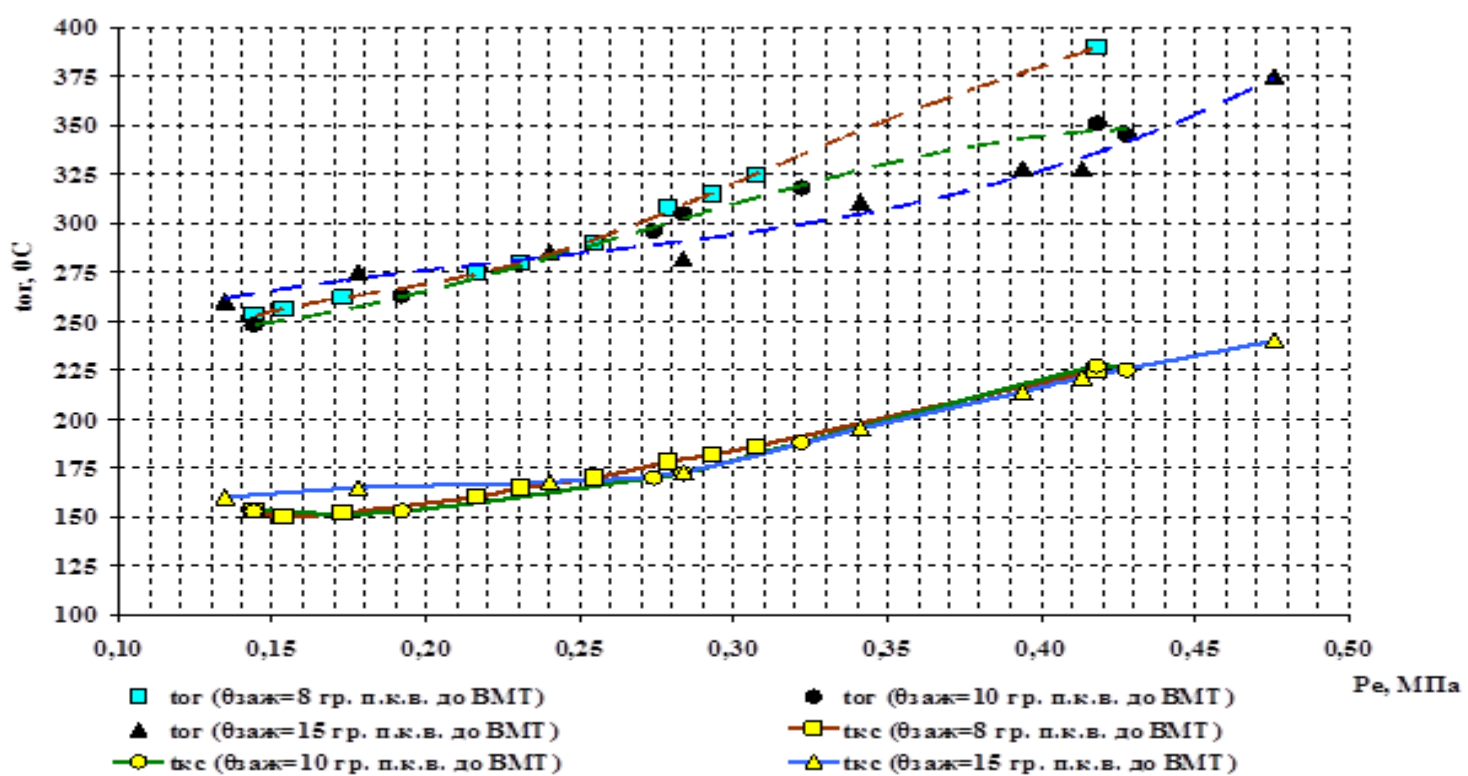

Рис. 2. Значения температур $\mathrm{t}_{\text {ог }} \mathrm{t}_{\mathrm{kc}}$ по нагрузочной характеристике при $\mathrm{n}=3000$ мин $^{-1}$ 


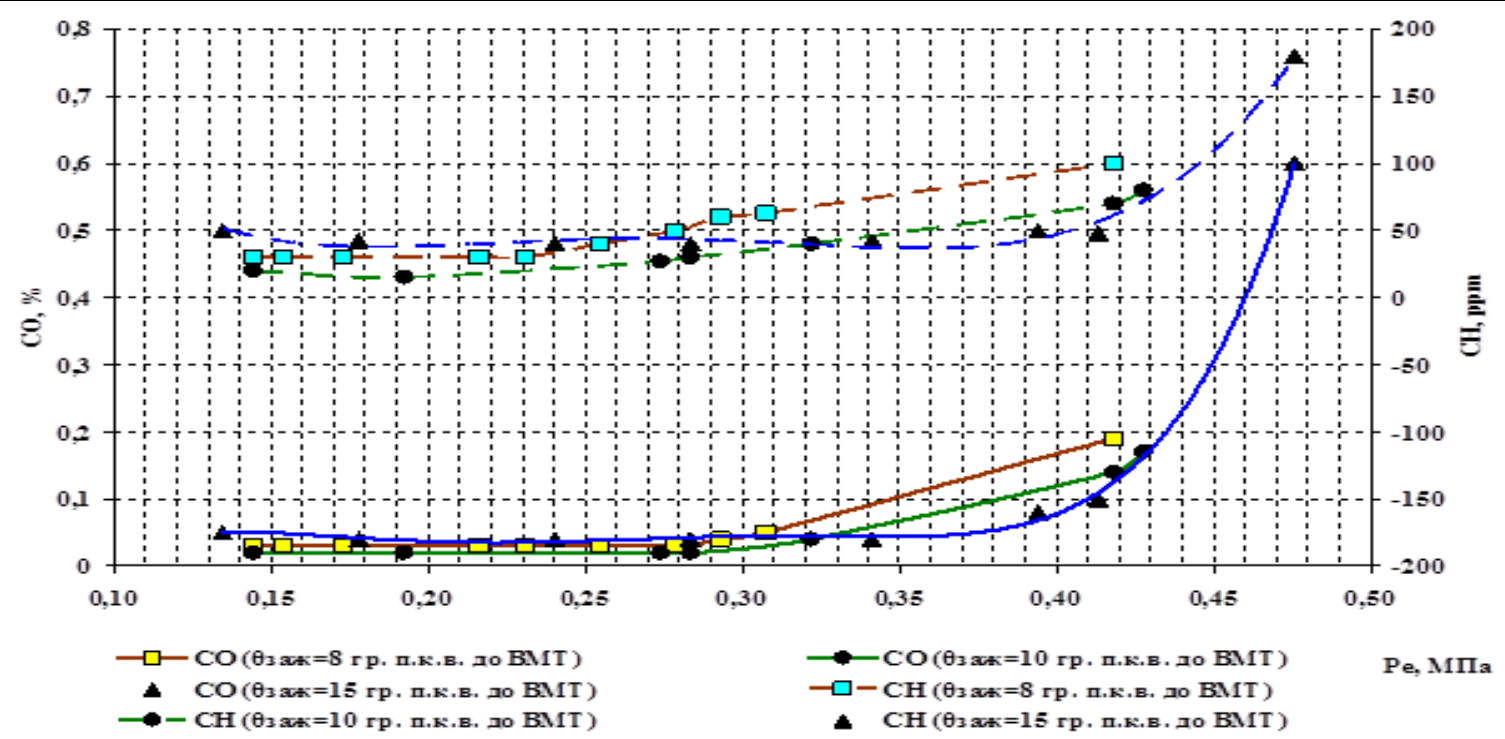

Рис. 3. Содержание $\mathrm{CO}$ и СН в ОГ по нагрузочной характеристике при $\mathrm{n}=$ 3000 мин $^{-1}$

\section{Список использованных источников}

1. Архангельский В.М. Автомобильные двигатели [Текст] / В.М. Архангельский, М.М. Вихерт, А.Н. Воинов [и др.] - М.: Машиностроение, 1977. - 591 с.

2. Eichlseder H. Grundlagen und Technologien des Ottomotors. [Текст] / Н. Eichlseder, M. Klüting, W.F. Piock. Der Fahrzeugantrieb Springer Wien New York, 2008. - 264 p.

3. Ferguson Colin R. Internal Combustion Engines: Applied Thermosciences Second Edition.[Текст] /R. Ferguson Colin, T. Kirkpatrick Allan. John Wiley \& Sons. Inc., 2001. - 384 p.

4. Basshuysen R. Ottomotor mit Direkteinspritzung: Verfahren, Systeme, Entwicklung, Potenzial [Текст] / R.Basshuysen Aufl. Springer Fachmedien Wiesbaden, 2013. - 480 p.

5. Zhao H. Advanced Direct Injection Combustion Engine Technologies and Development Gasoline and Gas Engines, V. 1. - 2010 [Текст] / H. Zhao. Woodhead Publishing Limited and CRC Press LLC, 2010. - 324 p.

$\begin{array}{llllll}\text { 6. Пат. } 87733 & \text { C2, Україна, }\end{array}$ Спосібсумішоутвореннявкамерізгоряннядвигунавнутрішньогозгорянняідвигунвнутрішньогоз горяннязрозшаруваннямпаливоповітряногозарядутаізпримусовимзапалюваннямприбезпосер едньомувприскуванніпалива / [КорогодськийВ.А., КирилюкI.О., ЛомовС.Г.]; заявник і власник - КорогодськийВ.А., КулигінВ.І., КирилюкІ.О., ЛомовС.Г. - №a200710939; заявл. 03.10.2007; опубл. 10.08.2009, Бюл. № 15.

7. Корогодский В.А. Организация рационального способа регулирования мощности в двигателе с искровым зажиганием [Текст] / В.А. Корогодский // Двигатели внутреннего сгорания. - Харьков, 2013. - №1. - С. 11-16.

8. GünterP. Merker. GrundlagenVerbrennungsmotorenFunktionsweise, Simulation, Messtechnik [Текст] / P. GünterMerker. SpringerFachmedienWiesbaden, 2014. - 1132 p.

9. Корогодский. В.А. Повышение топливно-экологических показателей двухтактного ДВС с искровым зажиганием за счет совершенствования процессов внутреннего смесеобразования [Текст] / В.А. Корогодский // Двигатели внутреннего сгорания. - Харьков, 2013. - №2. - C. 21-26.

10. Ковылов Ю.Л. Теория рабочих процессов и моделирование процессов ДВС [Текст]: учеб. пособие / Ю.Л. Ковылов. - Самара: СГАУ, 2013. - 416 с.

11. Konrad Reif. Ottomotor-Management Steuerung, Regelung und Überwachung [Текст] /Reif Konrad. Springer Fachmedien Wiesbaden, 2014. - 466 p. 


\section{Теплові двигуни}

Корогодский Владимир Анатольевич канд. техн. наук, доцент, кафедра теплотехники и тепловых двигателей. Украинская государственная академия железнодорожного транспорта. Тел.:(057) 730-10-78. E-mail: korogodskiy@mail.ru

Стеценко Оксана Николаевна аспирант, кафедра теплотехники и тепловых двигателей. Украинская государственная академия железнодорожного транспорта.

Tel.:(057) 730-10-78. E-mail: stetsenko.oksana@mail.ru

Обозный Сергей Владимирович научный сотрудник, кафедра двигателей внутреннего сгорания. Национальныйтехническийуниверситет «ХарьковскийПолитехническийИнститут».

Korohodskiy Volodymyr Anatolyovych candidate of technical science, associate professor department of heating engineering and heat engines. Ukrainian State Academy of Railway Transport. Tel.:(057) 730-10-78. E-mail: korogodskiy@mail.ru

Stetsenko Oksana Nikolaevna postgraduate, department of heating engineering and heat engines. Ukrainian State Academy of Railway Transport. Tel.:(057) 730-10-78. E-mail: stetsenko.oksana@ mail.ru

Obozniy SergeyVladymyrovychresearch associate, department of internal combustion engines.National Technical University "KPI". 